\title{
A Model Municipal By-Law for regulating wood burning appliances
}

\author{
A. Germain, F. Granger \& A. Gosselin \\ Environment Canada, Environmental Protection Operations Division, \\ Montreal, Canada
}

\begin{abstract}
This paper describes a Model Municipal By-Law, developed to support municipal or local governments that wish to control air pollution caused by the use of residential wood burning for heating purposes. Wood burning is the most important anthropogenic source of fine particulates $\left(\mathrm{PM}_{2.5}\right)$ in Canada. As a complement to a national regulation on new, cleaner burning wood burning appliances, initiatives were identified to address existing appliances. These initiatives include public outreach and a change-out program. As a result, a Model Municipal By-Law for regulating wood burning appliances was developed as an aid to local governments that want to regulate the use of residential wood burning appliances for residential use on their territory.

Keywords: residential wood combustion, emission, regulation, municipal by-law.
\end{abstract}

\section{Introduction}

In 2000, the Canadian Council of Ministers of the Environment developed a Canada-wide Standard for particulate matter less than or equal to 2.5 microns (also known as fine particulate or $\mathrm{PM}_{2.5}$ ) as a result of the pollutant's adverse effects on human health [1]. It also indicated that measures where to be taken to reduce their emissions, including those from residential wood combustion for heating purpose [2].

This document is intended as an aid for municipalities where air quality problems due to residential wood burning are experienced and who therefore wish to put in place a municipal by-law for regulating woodburning appliances. The workshop summary of the Kelowna Residential Indoor Wood Burning 
By-Law Workshop [3] served as a starting point for developing this document, as well as responses received by 17 out 26 Canadian and American jurisdictions invited to share their experience regarding the implementation and performance of their own by-laws.

\section{Atmospheric emissions from residential wood combustion}

There were approximately 3.6 million wood-burning appliances installed in Canada in 1997, distributed between fireplaces (almost 2 millions), wood stoves (1.3 millions) and central furnaces or boilers (0.3 million) [4]. Approximately 0.25 million $(7 \%)$ of them were advanced technology appliances that comply with the United States Environmental Protection Agency's (EPA) Standards of Performance for New Residential Wood Heaters (40 CFR Part 60, Subpart AAA) [5] or the standard B415.1-00 of the Canadian Standard Association (CSA) [6]. We also refer to them as "certified" appliances or wood stoves.

Residential wood heating fulfils only $1 \%$ of Canada's energy demand yet it is responsible for $29 \%$ of the fine particulate matter $\left(\mathrm{PM}_{2.5}\right)$ and $48 \%$ of the polycyclic aromatic hydrocarbons (PAHs) emitted by all Canadian sources combined (excluding forest fires and dust from paved roads and unpaved roads). New-technology fireplaces and wood stoves that comply with the CSA's standard B415.1-00 or the Standards of Performance for New Residential Wood Heaters of the U.S. Environmental Protection Agency (U.S. EPA) have much lower levels of polluting emissions than non-certified appliances. The replacement, in whole or in part, of old wood-burning appliances with state-ofthe-art units would reduce emissions of PM2.5, PAHs, volatile organic compounds (VOCs) and carbon monoxide (CO) by the home heating sector by 30 to $55 \%$ and lead to a $10 \%$ drop in emissions of greenhouse gases (GHG). Considering the lifespan of a wood stove, it could take another 20 to 40 years before those appliances currently in use are replaced.

Table 1 presents some of the Criteria Air Contaminants (CAC), PAH, D/F and GHG emissions data for different sectors of activity. For the purposes of comparison, the emissions of other sources of residential fuel combustion and total Canadian emissions (with and without open sources) are also presented. Fine particulate $\left(\mathrm{PM}_{2.5}\right)$, volatile organic compounds (VOCs) and carbon monoxide (CO) emission values were taken from Environment Canada's 2000 CAC Emissions Inventory [7]. The PAH emissions were taken primarily from the 1990 inventory prepared for the toxicity assessment of PAHs [8], except for residential wood combustion and the industrial sector. Emissions for residential wood combustion were calculated considering the amount of wood burned in Canada and emission factors derived from Fisher et al. [9] and from Valenti and Clayton [10]; for the industrial sector, PAH emissions from a 1990 inventory were updated to reflect emission reductions in the aluminium sector up to the year 2000. The dioxin and furan values come from Environment Canada's D/F Inventory [11] and the greenhouse gas values were taken from the Canadian GHG Inventory for 2000 [12]. 
Air Pollution XVI 629

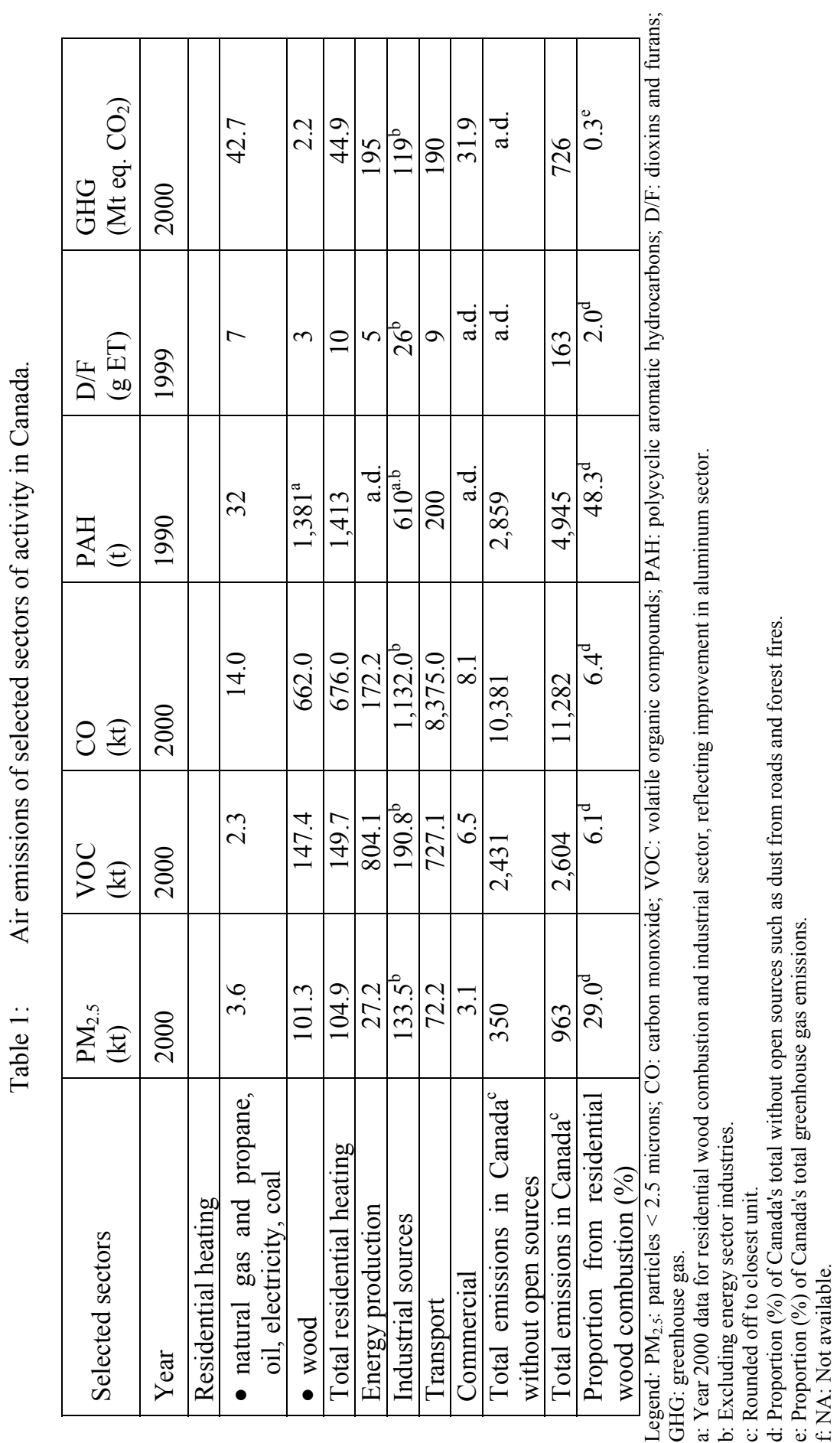




\section{Residential wood combustion control strategy in Canada}

Environment Canada has worked on four inter-related elements to address the air emission from residential wood combustion is comprised of four inter-related elements. These four elements are:

1. Update of the Canadian Standard Association (CSA) B415-1.00 Standard on residential wood combustion appliances.

2. Integration of the CSA Standard in a regulation controlling the sale as well as the import and manufacture for sale of residential wood combustion appliances.

3. Public education and outreach.

4. Promote the change of existing old technology appliances for new certified appliances.

The first two elements address the new woodstoves and central-heating boilers coming into use. They will ensure that all new appliances sold in Canada are certified, cleaner burning appliances. However, once installed, a wood burning appliance will have an impact on air quality for a long period of time. The wood stove industry in Australia suggests that their working lifespan is 15 to 20 years [13] and an American source mentions that good-quality wood stoves can be expected to last 40 years [14]. In view of this slow turnover rate, other measures could be used to reduce emissions and their impact on air quality.

The two other elements of the strategy are meant to address existing, in-use appliances. The first one is a public education and outreach program. Its objective is to inform the general public on the impact of wood combustion on air quality and health, as well as the consumer's choice, technology and practices to reduce that impact.

The last two elements could help achieve a faster turnover rate of old technology stove to cleaner burning certified stoves by influencing the choice of the consumer in favour of the stoves using the best technology (certified stoves). This is appropriate when there are no regulations in place to limit the availability of conventional, uncertified appliances on the market. It could be more efficient if incentive reducing the price differential between advanced technology stoves and conventional stoves enough to shift consumer choice significantly was provided. However, it is not actually considered because of the elevated costs involved.

Another type of economic instrument, the change-out programs, is designed to accelerate the turnover rate by convincing the consumer to exchange its old technology stove for a certified one sooner than he would have without the incentive. These programs are best suited to local or regional scopes and are more efficient if coupled with a strong public education component. 


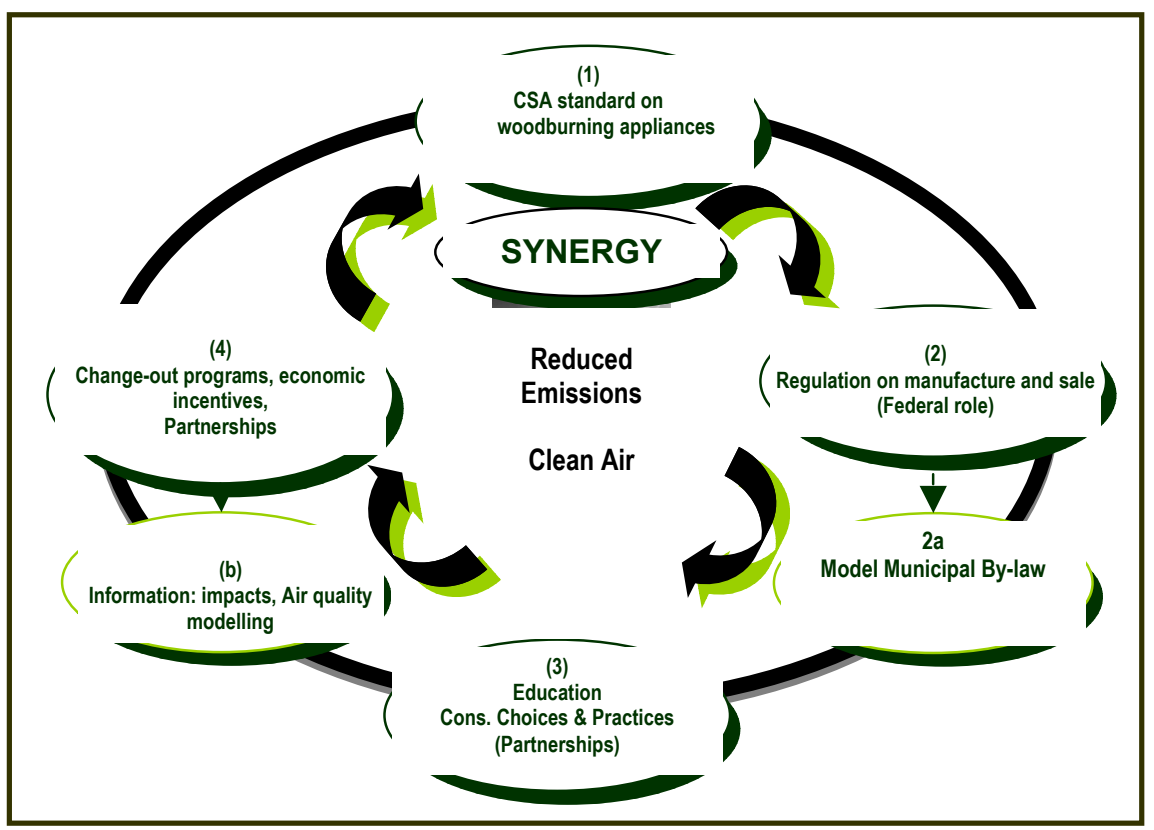

Figure 1.

\section{Role of municipal governments in air quality management}

The set of national-wide measures proposed in the strategy may not be sufficient to ensure that air quality problems associated with residential wood combustion are properly addressed everywhere in Canada. In certain areas, most notably where there is a dense concentration of wood burners and/or topographical or adverse weather conditions, a high concentration of fine particulates can result, and may indicate that wood burning may not be suitable in that area. In some cases, those conditions are only temporary; in other situations they are chronic and may require a controlled or more regulated approach to wood burning. In these instances, the most efficient approach may be through municipal governments. In that respect, the federal and provincial governments are best placed to control the entry of new appliances on the market, through regulating the sale, import and manufacture of appliances. The municipal or regional authorities are best placed to control the installation and use of residential wood combustion appliances.

\section{Objective of the Model Municipal By-Law}

However, many municipalities lack resources and expertise to design and implement efficient regulatory instruments to adequately manage air issues associated with residential wood combustion. The lack of adequate support to local governments who choose to regulate the use of wood as a residential 
energy source was indicated by stakeholders as an issue needing to be addressed. The model municipal by-law has been produced by Environment Canada in collaboration with representatives from the industry, municipalities, provincial and territorial governments, and environmental non-governmental organizations, under the Intergovernmental Working Group on Residential Wood Combustion (IGWGRWC). This document is a tool to be used by a municipality wishing to develop and put in place a municipal by-law to regulate wood burning appliances. It is intended to be used by municipalities that experience air quality problems because of residential wood combustion. This Model Municipal ByLaw presents control strategies and options that may be adopted by municipal or regional authorities on residential wood burning. The appendix of the document contains elements of a model municipal by-law with the wording of control strategies and options contemplated to address reduction and control of particulate matter emissions.

\section{Type strategies described in the Model By-Law}

The control strategies presented in the Model By-Law can be categorized as follows.

- Strategies that specify limits on total emissions, measured either as a unit of production or as a reduction in emissions relative to a baseline. These include emission limits for wood burning appliances and mandatory curtailment strategies.

- Strategies that provide incentives or impose disincentives to limit emissions rather than making reductions compulsory. These include financial assistance strategies to encourage change-out of non-certified wood burning appliances and mitigation offset strategies.

- Strategies that do not yield quantifiable emission reductions, but still contribute to an area's overall attainment of air quality standards. These include public education and information strategies.

These strategies comprehensively address particulate matter pollution by establishing regulatory mechanisms, offering financial incentives and assistance and providing education and information. Municipalities can employ a mix of all three strategies. The document provides supporting information for the following control options.

- $\quad$ Restriction on Some Fuels. - The restrictions prohibit use specific fuels that promote adverse air quality conditions. These fuels include wet or unseasoned wood, garbage, plastics, treated wood, rubber products, waste oils, paint, solvents etc.

- Installation of wood burning Appliances. - This by-law would prohibit the installation of wood burning appliances that do not meet specific standards, for example Canadian Standard Association (CSA) standard or the US EPA standard.

- $\quad$ Non-certified Appliance Removal. - An example of such strategy is a provision that requires that, prior to the completion or consummation of a sale or transfer of any real property on or after a certain date, all 
existing wood burning appliances that are not certified shall be replaced, removed or rendered permanently inoperable.

- No Burn Days. - The local authority may issue a declaration of an "Air Quality Advisory Period" through local communications media that would result in voluntary or mandatory curtailment of the use of noncertified or all wood burning appliances whenever conditions within the region are projected to cause ambient air quality concentrations of $\mathrm{PM}_{2.5}$ that exceed a certain level (micrograms per cubic meter).

- $\quad$ Nuisance. - This strategy applies a nuisance by-law where woodburning appliance fires shall be maintained so as not to cause a nuisance for more than two minutes in succession except during a thirty-minute period following the starting or re-fuelling of the appliance.

- Opacity. - This strategy applies an opacity limit where, within the municipality, no person owning or operating a wood burning appliance shall at any time cause, allow or discharge emissions of an opacity greater than twenty (20) percent

- Outdoor Solid-fuel Combustion Appliances. - This strategy applies restriction to the installation and use of outdoor air or water heater. These types of appliances are not subjected to an enforceable standard as yet, and present a growing air quality issue in Canada.

For each control strategy, the following information is provided.

- Description. - A narrative of the strategy describing what and how the strategy may be accomplished.

- Target. - The particulate matter sources, type of development and emission goals that the strategy is intended to address.

- Advantages. - Various factors that support the strategy.

- Disadvantages. - Various factors that weigh against the strategy.

- Costs to private citizens. - The potential implementation costs of the strategy that will be directly passed on to the private citizens.

- $\quad$ Costs to the public sector. - The potential implementation costs to the municipal government and other public agencies. These costs may be considered indirect costs to the citizens.

- Emission savings. - Reductions from current levels of emissions and emission concentrations anticipated upon implementation of the strategy.

- Enforcement. - A discussion on how the strategy will be enforced to ensure compliance.

- Implementation guidelines. - Guidelines on how the strategy should be effectively implemented. This section often refers to the need for an education component.

- Who is doing it? - A non-exhaustive list of Canadian and United States jurisdictions that have implemented a similar control strategy

In addition to these control options supporting information is also provided on the emission offsets programs as well as awareness, education and communication strategies 


\section{Conclusion}

At the moment, there are very few municipalities that have adopted, or even are planning to adopt a regulatory approach regarding residential wood combustion within their jurisdiction. The Model Municipal By-Law for Regulating Woodburning Appliances was published in 2006. It was initially distributed to more than 200 municipalities in Canada. Since then, at least one Canadian municipality has used the guide to prepare and adopt a by-law on residential wood combustion. However with increasing public awareness of the air quality and health issues resulting from the residential wood combustion, it is reasonable to think that public pressure will drive more local governments to consider this course of action.

\section{References}

[1] CCME, Canada-Wide Standards for Particulate Matter (PM) and Ozone, 2000, Online. http://www.ccme.ca/assets/pdf/pmozone_standard_e.pdf

[2] CCME, Joint Initial Actions to Reduce Pollutant Emissions that Contribute to Particulate Matter and Ground-level Ozone, 2000. Online. http://www.ccme.ca/assets/pdf/pmozone_joint_actions_e.pdf

[3] Workshop Summary, Residential Indoor Wood Burning Bylaw Workshop, 2002. Online.

http://www.bvldamp.ca/pdf/rcsh/BurnBylawFinalSummary.pdf

[4] Niemi, D. 2002-2003. Personal communications. Head, Emissions Inventory Reporting and Outreach, Environment Canada, Pollution Data Branch.

[5] Subpart AAA - Standards of Performance for New Residential Wood Heaters; United States Environmental Protection Agency. Online. http://www.epa.gov/compliance/resources/policies/monitoring/caa/woodsto verule.pdf

[6] B415.1-00 Performance Testing of Solid-Fuel-Burning-Heating Appliances, CSA International, Toronto, 2000

[7] Criteria Air Contaminants Emission Summary, Environment Canada. Online. http://www.ec.gc.ca/pdb/cac/Emissions1990-2015/emissions19902015 e.cfm

[8] LGL - Lavalin-Girouard-Letendre, PAH Emissions into the Canadian Environment, 1990. Supporting Document No. 1 for the National Evaluation Report on PAHs. Report prepared by M. Fabbri-Forget for Environment Canada, Conservation and Protection, Quebec Region, Montreal, Quebec. 1993.

[9] Fisher, L.H., J.E. Houck, P.E. Tiegs, \& J. McGaughey, Long-Term Performance of EPA-Certified Phase 2 Woodstoves, Klamath Falls and Portland, Oregon: 1998-1999. Report prepared for U.S. EPA, EPA contract 68-D7-001, WA 2-04, Washington, DC., 2000. Online. http://www.omnitest.com/Publications/Long-Term.pdf. 
[10] Valenti, J.C. \& R.K. Clayton, Project Summary Emissions from Outdoor Wood-Burning Residential Hot Water Furnaces. Report EPA/600/SR98/017. National Risk Management Research Laboratory, Research and Development, U.S. EPA, Cincinnati, OH., 1998. Online. http://www.epa.gov/ttn/atw/burn/woodburn1.pdf

[11] Environment Canada, Inventory of Releases of PCDDs and PCDFs (updated February 2001). Report prepared for Environment Canada and the Federal/Provincial Working Group on Dioxins and Furans for the FederalProvincial Advisory Committee for the Canadian Environmental Protection Act (CEPA-FPAC), Ottawa, Ontario 2001

[12] Olsen, K., P. Collas, P. Boileau, D. Blain, C. Ha, L. Henderson, C. Liang, S. McKibbon, \& L. Morel-à-l'Huissier, Canada's Greenhouse Gas Inventory 1990-1999. Environment Canada, Greenhouse Gas Division, Ottawa, Ontario. 2002.

[13] Environment Australia, Technical Report No. 4: Review of Literature on Residential Firewood Use, Wood-Smoke and Air Toxics, 2002. Online. http://ea.gov.au/atmosphere/airtoxics/report4/exec-summary.html.

[14] Houck, J.E. \& P.E. Tiegs, Residential Wood Combustion: PM $_{2.5}$ Emissions. Outline of presentation prepared for WESTAR PM..5 Emission Inventory Workshop, Reno, Nevada, July 22-23, 1998. Online. http://www.omnitest.com/Publications/westar.pdf 